Accelerator Department

BROOKHAVEN NATIONAL LABORATORY

Associated Universities, Inc.

Upton, L.I., N.Y。

EP \& S DIVISION TECHNICAL NOTE

\author{
No. 2 \\ A.L. $\operatorname{Read}^{*}$ \\ March 10, 1967 \\ THE $6-10+4.7^{\circ}$ PION BEAM $(4-16 \mathrm{GeV} / \mathrm{c})$ AT THE BROOKHAVEN
}

We describe briefly the beam transport system for the G-10 $+4.7^{\circ}$ intermediate energy $(4-16 \mathrm{GeV} / \mathrm{c})$ beam at the AGS. The data supplied here are current as of March 1967. It is not anticipated that the upstream end of the beam $\left(Q_{1+6}\right.$ and $D_{1}$ in Fig. I) will be moved in the near future ${ }^{1}$. However, the remaining components of the beam may sometimes be rearranged, but the general properties of the system should not be greatly affected by such changes. The original layout of the $4.7^{\circ}$ pion beam (1964-5) has already been described in some detail ${ }^{2}$ and is illustrated in Fig. I. For a description of the design criteria and the methods used for optimizing the beam layout, see Reference 2 .

The G-10 target is usually a 30-mil diameter, L-shaped Be wire. Most of the p-Be interactions which yield the desired pions take place in the horizontal arm of the "L", which is $\frac{1}{2}$ " in length and is pointed along the axis of the $10^{\circ}$ separated $\mathrm{K}^{-}$beam (Separated Beam 非5). The effective horizontal dimension of the target is thus about 70-mils.

A schematic drawing of the beam optics is shown in Fig. II. Lens $L_{1}$ focusses the beam from the production target $\mathrm{T}$ at a slit $\mathrm{S}$ ("intermediate focus"). The beam is dispersed by the deflection manget $\mathrm{D}_{1}$; the band of desired momenta passes through the slit $\mathrm{S}$. The $\Delta \mathrm{p} / \mathrm{p}$ bandpass is proportional to the width of the aperture of $\mathrm{S}$ ( $\frac{1}{2} "$ slit corresponds to $\Delta \mathrm{p} / \mathrm{p}=2 \% \mathrm{FWHM}$ ). Variation of the height of the aperture of $\mathrm{S}$ is a convenient intensity control. Lens $\mathrm{L}_{2}$ refocusses the beam at the image point $I$. The momentum band accepted by the slit $S$ is recombined by the deflection magnet $D_{2}$ into an (almost) achromatic image at $I$.

* Laboratory of Nuclear Studies, Corne11 University, Ithaca, New York 
Tables I,II and III give lists of the beam elements, the separation distances between them, and the values of other relevant parameters (fields, apertures, etc.). The field values given are the results of beam-tuning done in a recent experiment. ${ }^{3}$ In general, the field values used agree, within $1-2 \%$, with values caleulated using beam-transport beam programs. Note that the value of the field in $D_{I}$ depends upon the radial position of the production target, $R_{T}$. However, any value of $R_{T}$ can be made to yield the same intensity as the $4.7^{\circ}$ beam. Note also that the fields of $Q_{I}$ and $D_{I}$ do not depend linearly upon the particle momentum. These are consequences of the effect of the fringe field of the AGS G-11 magnet on the trajectories of the particles in the secondary beam.

To tune the beam, the following procedure has been followed in the past. First, set the magnetic fields at the values indicated in Table $I_{\text {. Keep }} \mathrm{D}_{2}$ fixed - this is used as the definition of momentum. Then maximize the beam flux by adjusting, in turn, $D_{1}, Q_{1}, Q_{3}, Q_{5}, Q_{7}, Q_{9}, Q_{9}, D_{1} \circ \quad$ (This is the order used in the present Corne11-BNL collaboration experiment ${ }^{3}$ ). 
TABLE I

Beam Components

Positions and Apertures of Components

\section{Component Type}

1. Fringe field

2. Free Space

3. $Q 1, N 8 Q 32$

4. Free Space

5. Q2, N8Q32

6. Free Space

7. $\mathrm{Q} 3,8 \mathrm{Q} 48$

8. Free Space

9. $Q 4,8 Q 48$

10. Free Space

11. $Q 5,8 Q 48$

12. Free Space

13. Q6, $8 \mathrm{Q} 48$

14. Free Space

15. D1, 18D72

16. Free Space

17. Collimator C

18. Free Space

19. D2, 18D72
Length

199

97

34

36

34

17

52

8

52

8

52

8

52

12

80

362

40

257

80
Distance of Downstream End of Component From Beam Origin

199

296

330

366

400

417

469

477

529

537

589

597

649

661

741

1,103

1,143

1,410

1,490
18"Hor.x6"Vert.

Aperture

Remarks

In this region particle trajectories can be calculated with BEAM program ${ }^{4}$.

8"diameter Vertically

focussing

8"diameter Vertically

focussing

8"diameter

8"diameter

Vertically

focussing

8"diameter

Vertically

focussing

Deflection angle: $2.89^{\circ}$

$\mathrm{cW}$

Typical 1 y
$\frac{1}{2} y_{1}$ Hor. $x^{\frac{1}{2}}{ }^{\prime \prime}$ Vert.

"Intermediate focus" $\frac{13}{4} " x^{\frac{1}{4}} "=$ $\pm \frac{1}{2} \% \Delta \mathrm{p} / \mathrm{p}$

$\frac{1}{2} " x^{\frac{1}{2}} "= \pm 1 \%$ :

$1^{\prime \prime} x 1^{\prime \prime}= \pm 2 \%$

18"Hor •x6"Vert.
Deflection angle: $1.99^{\circ}$ 
TABLE I (cont.)

Component Type

20. Free Space

21. Q7, 8Q48

22. Free Space

23. Q8, $8 \mathrm{Q} 48$

24. Free Space

25. Q9, 8Q48

26. Free Space

\section{Length}

57

52

124

52

111

52

1,161

\section{Distance of Down- stream End of Com- ponent From Beam Origin}

1,547

1,599

1,723

1,775

1,886

1,938

3,099
Aperture

Remarks

8" diameter

Horizonta11y

focussing

8" diameter

Vertica11y

focussing

8" diameter

Horizonta11y focussing

Target for experiment 
TABLE II

Beam Components

Current Strengths for Deflection Magnets (for $R_{T}=+1.1^{\prime \prime}$ )

\begin{tabular}{|c|c|c|c|}
\hline $\begin{array}{l}\text { Momentum } \\
(\mathrm{GeV} / \mathrm{c})\end{array}$ & Polarity & $\begin{array}{c}I(D 1) \\
\text { (Units are shunt millivolts) } \\
(40 \mathrm{~A} / \mathrm{mV})\end{array}$ & $\begin{array}{l}\text { I(D2) } \\
\text { (Units are shunt millivolts) } \\
(40 \mathrm{~A} / \mathrm{mV})\end{array}$ \\
\hline 6 & - & 13.3 & 13.5 \\
\hline 6 & + & 14.3 & 13.5 \\
\hline 10 & - & 22.5 & 22.5 \\
\hline 10 & + & 23.8 & 22.5 \\
\hline 14 & - & 31.8 & 31.5 \\
\hline 14 & + & 32.7 & 31.5 \\
\hline 16.5 & - & 37.9 & 37.5 \\
\hline 17.5 & + & 41.2 & 39.4 \\
\hline
\end{tabular}


TABLE III

Beam Components

Field Strengths for Quadrupoles (for $\mathrm{R}_{\mathrm{T}}=+1.1^{\prime \prime}$ )

\begin{tabular}{|c|c|c|c|c|c|c|c|c|c|}
\hline $\begin{array}{l}\text { Momentum } \\
(\mathrm{GeV} / \mathrm{c})\end{array}$ & Polarity & $\begin{array}{c}\text { I (Q1) } \\
\text { units } \\
\text { are } \\
\text { shunt } \\
\text { mV } \\
25 \mathrm{~A} / \mathrm{mV}) \\
\end{array}$ & $\begin{array}{c}\mathrm{I}(\mathrm{Q} 2) \\
\text { units } \\
\text { are } \\
\text { shunt } \\
\mathrm{mV} \\
(40 \mathrm{~A} / \mathrm{mV})\end{array}$ & $\begin{array}{c}\text { I (Q3) } \\
\text { units } \\
\text { are } \\
\text { shunt } \\
\text { mV } \\
(25 \mathrm{~A} / \mathrm{mV}) \\
\end{array}$ & $\begin{array}{c}\mathrm{I}(\mathrm{Q} 4) \\
\text { units } \\
\text { are } \\
\text { shunt } \\
\mathrm{mV} \\
(25 \mathrm{~A} / \mathrm{mV})\end{array}$ & $\begin{array}{l}\mathrm{I}(\mathrm{Q} 5,6) \\
\text { units } \\
\text { are } \\
\text { shunt } \\
\mathrm{mV} \\
(25 \mathrm{~A} / \mathrm{mV}) \\
\end{array}$ & $\begin{array}{c}\text { IfQ7) } \\
\text { units } \\
\text { are } \\
\text { shunt } \\
\mathrm{mV} \\
(25 \mathrm{~A} / \mathrm{mV})\end{array}$ & $\begin{array}{c}\mathrm{I}(\mathrm{Q} 8) \\
\text { units } \\
\text { are } \\
\text { shunt } \\
\mathrm{mV} \\
(40 \mathrm{~A} / \mathrm{mV})\end{array}$ & $\begin{array}{c}\text { I (Q9) } \\
\text { units } \\
\text { are } \\
\text { shunt } \\
\mathrm{mV} \\
(25 \mathrm{~A} / \mathrm{mV})\end{array}$ \\
\hline 6 & - & 29.0 & 23.5 & 27.3 & 27.5 & 13.0 & 20.5 & 22.0 & 24.0 \\
\hline 6 & + & 23.5 & 23.0 & 27.5 & 27.5 & 13.0 & 18.3 & 21.7 & 24.3 \\
\hline 10 & - & 49.0 & 36.5 & 46.5 & 46.0 & 22.8 & 31.0 & 36.7 & 40.8 \\
\hline 10 & + & 41.8 & 37.0 & 46.5 & 46.0 & 22.8 & 31.7 & 36.7 & 40.8 \\
\hline 14 & - & 70.0 & 51.5 & 64.0 & 63.5 & 31.0 & 48.0 & 51.5 & 54.5 \\
\hline 14. & + & 59.0 & 51.0 & 65.0 & 63.5 & 31.5 & 46.0 & 51.5 & 54.5 \\
\hline 16.5 & - & 85.5 & 56.0 & 75.7 & 74.5 & 36.8 & 50.0 & 64.5 & 66.0 \\
\hline 17.5 & + & 85.0 & 59.4 & 80.2 & 79.3 & 39.0 & 53.0 & 64.0 & 70.0 \\
\hline
\end{tabular}




\section{References}

1. J.R. Sanford, private communication

2. A.L. Read and R. Rubinstein, Brookhaven National Laboratory Report BNL-9213

3. 1967 Corne11-BNL Collaboration; J. Orear, A.L. Read, R. Rubinstein, D.H. White, et al.

4. E.D. Courant: Brookhaven National Laboratory, Accelerator Department Internal Report EDC-36 


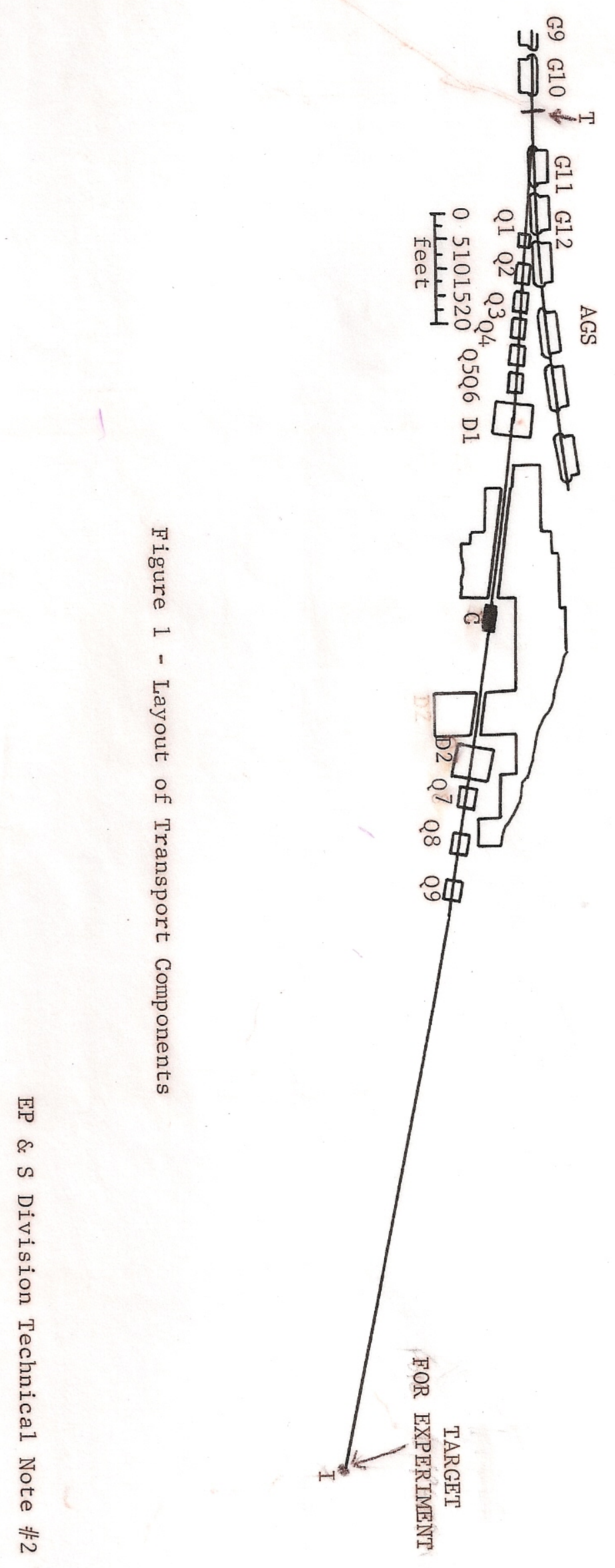




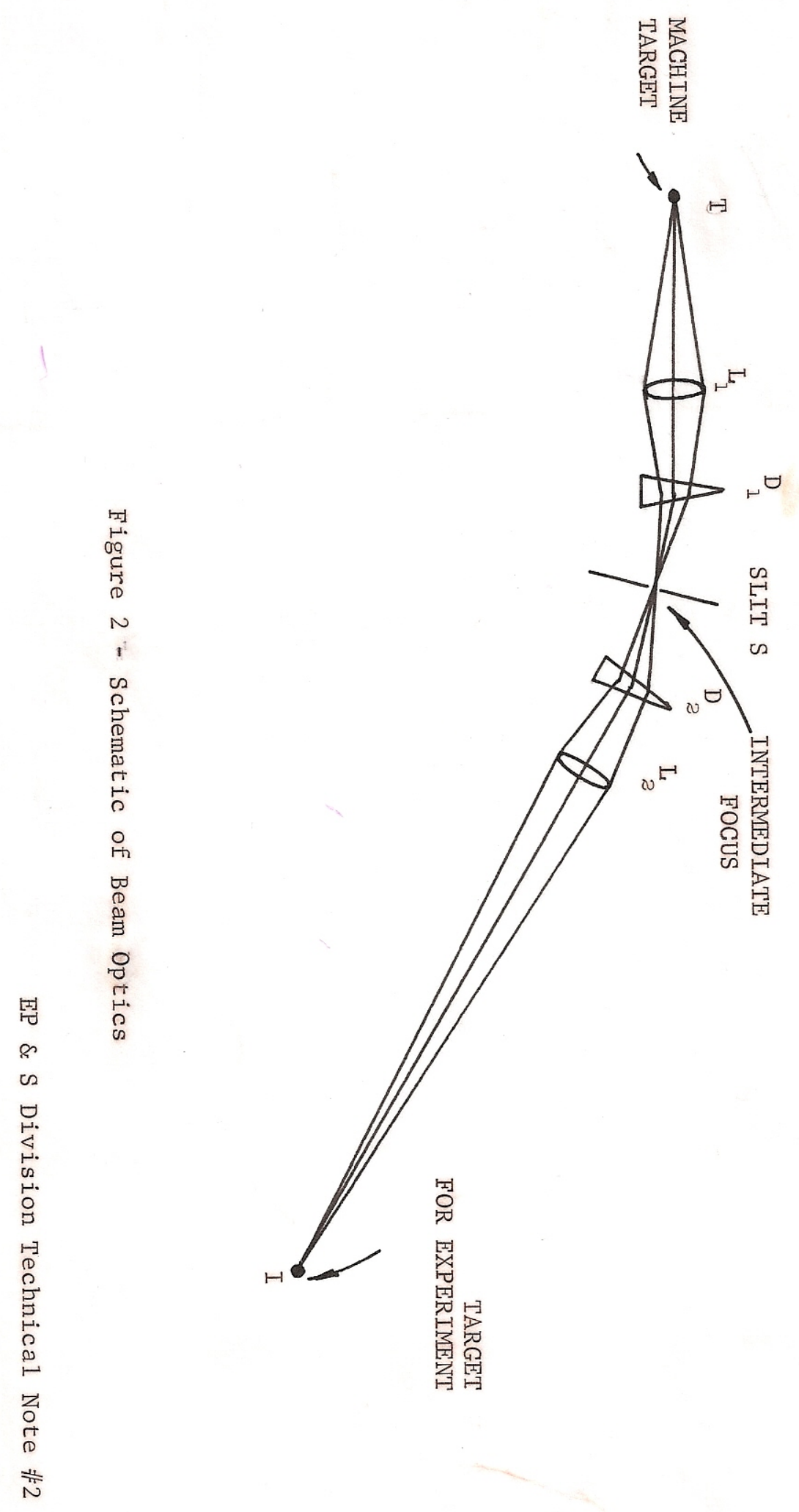

